\title{
Hypertensive Disorders of Pregnancy Appear Not to Be Associated with Alzheimer's Disease Later in Life
}

\author{
Carolien N.H. Abheiden ${ }^{a} \quad$ Rebecca van Doornik $^{a} \quad$ Annet M. Aukes ${ }^{a}$ \\ Wiesje M. van der Flier ${ }^{b, c}$ Philip Scheltens ${ }^{b} \quad$ Christianne J.M. de Groot ${ }^{a}$ \\ a Department of Obstetrics and Gynecology, VU University Medical Center, and ${ }^{b}$ Alzheimer \\ Center, Department of Neurology, and ' Department of Epidemiology and Biostatistics, VU \\ University Medical Center, Neuroscience Campus Amsterdam, Amsterdam, The Netherlands
}

\section{Key Words}

Alzheimer's disease - Magnetic resonance imaging · Preeclampsia · Pregnancy-induced hypertension · Early-onset dementia

\begin{abstract}
Background: After hypertensive disorders of pregnancy, more subjective cognitive complaints and white matter lesions are reported compared to women after normal pregnancies. Both have a causal relationship with Alzheimer's disease (AD). Aim: To investigate if women whose pregnancy was complicated by hypertensive disorders have an increased risk of AD. Methods: A case-control study in women with AD from the Alzheimer Center of the VU University Medical Center Amsterdam and women without AD. Paper and telephone surveys were performed. Results: The response rate was $85.2 \%$. No relation between women with $(n=104)$ and without $A D(n=129)$ reporting pregnancies complicated by hypertensive disorders $(p=$ 0.11 ) was found. Women with early-onset $A D$ reported hypertensive disorders of pregnancy more often $(p=0.02)$ compared to women with late-onset AD. Conclusion: A reported history of hypertensive disorders of pregnancy appears not to be associated with AD later in life.
\end{abstract}

\section{Introduction}

Hypertensive disorders of pregnancy are a major cause of maternal and fetal morbidity and mortality [1-4] and the most common disorders in pregnancy; their prevalence is almost $10 \%[2,5,6]$. Hypertensive disorders of pregnancy is an umbrella term including preeclampsia

C.N.H. Abheiden and R. van Doornik are joint first authors. 
(systolic blood pressure $\geq 140 \mathrm{~mm} \mathrm{Hg}$ and/or diastolic blood pressure $\geq 90 \mathrm{~mm} \mathrm{Hg}$ and proteinuria $\geq 300 \mathrm{mg} / 24 \mathrm{~h}$ ), pregnancy-induced hypertension (hypertension as defined in preeclampsia, without proteinuria), eclampsia and elevated liver enzymes and low platelets (HELLP) syndrome. Despite extensive research, the exact causes of hypertensive disorders of pregnancy are still unknown. The main hypothesis is related to disturbed placental function in early pregnancy [7]. As a consequence, generalized endothelial dysfunction develops, through which preeclampsia potentially affects the perfusion of several organs including liver, kidneys and brain [7].

Until recently, the pathophysiological and clinical effects of hypertensive disorders of pregnancy, including cardiovascular and cerebrovascular dysfunction, were thought to be reversible. However, increasing evidence points out that hypertensive disorders of pregnancy are associated with long-term effects on women's health, e.g. increased risk of cardiovascular and cerebrovascular disease later in life [8-21].

Long-term effects on cerebrovascular disease after a pregnancy complicated by (pre)eclampsia have been observed, including a higher prevalence of subjective cognitive complaints such as memory, attention and concentration deficits after several years, compared to women with a history of pregnancies without hypertension [15-18]. Neuroimaging studies show evidence of long-term effects of (pre)eclampsia on the brain, including more frequent and larger cerebral white matter lesions compared to women who have had an uncomplicated pregnancy [19-21].

The clinical implications of the presence and larger volume of white matter lesions in relatively young women remains unclear $[17,22]$. In elderly patients, white matter lesions have been described and linked to subjective cognitive complaints and Alzheimer's disease (AD) pathology [23-28]. Subjective cognitive complaints can be the first sign of AD in elderly whose objective cognitive performance is normal [29]. Furthermore, white matter lesions on cerebral magnetic resonance imaging (MRI) correlate with subjective cognitive failure [30], and the severity of white matter lesions has been shown to predict the rate of cognitive decline over time [31,32]. These white matter lesions are suggested to play an important role in the pathogenesis of dementia [33-35]. The frequency of white matter lesions in women with AD varies $[32,36]$. Although the etiology of AD is still not completely elucidated, it is now known that the presence of cerebral white matter lesions, vascular risk factors and endothelial dysfunction contribute to its development [37-40].

Based on the above-described association between hypertensive disorders of pregnancy and white matter lesions, and white matter lesions and $\mathrm{AD}$, we hypothesize that women who have had a pregnancy complicated by hypertensive disorders are at increased risk of AD in later life.

\section{Materials and Methods}

Our study was a retrospective case-control study, in which we compared the reported prevalence of hypertensive disorders of pregnancy between women with AD and women without AD.

\section{Participants}

We identified women with AD from the database of the Alzheimer Center of the VU University Medical Center in Amsterdam. All women had previously given written consent to participate in scientific research. For the control group, we selected partners of male AD patients who gave their consent for participating in scientific research. 
Participants were included when they had at least one pregnancy continuing after 24 weeks' gestation. Women were excluded when they had a history of other types of neurodegenerative diseases, thromboembolisms, systemic lupus erythematosus or diabetes prior to their first pregnancy, or when nulliparous. Also, women with other forms of dementia like vascular dementia and mild cognitive impairment were excluded. The Medical Ethical Committee of the VU University Medical Center approved the study.

\section{Surveys}

We used self-report methods to gather data concerning obstetric complications. Recall of hypertensive disorders of pregnancy is adequate (up to 30 years after the event) according to a systematic review which was conducted to comprehensively review and assess the available literature on maternal recall of hypertensive disorders of pregnancy, so we hypothesized that recall, even in AD patients, would be sufficiently reliable [41].

Initially, we sent all our participants a paper survey for assessment. We used a questionnaire including items about demographic background, lifestyle, medical history and obstetric history [42]. The obstetric history items included the date of birth, number of pregnancies, parity, live births and stillbirths. Also, items concerning obstetric complications, i.e. hypertension, low-salt diet, proteinuria, toxemia (previous term for preeclampsia) or preeclampsia and seizures or eclampsia, were included. Since we expected that women would not remember their lab results in pregnancy, we did not specifically ask if they had HELLP syndrome in history. Age at AD diagnosis was collected from the database of the Alzheimer Center. Secondary to the initial paper survey, we performed a telephone survey in nonresponders to achieve an optimal response rate and prevent response bias. In both paper and telephone surveys, partners or family members were allowed to support the participants to help complete the surveys, to gather as much information as possible.

\section{Cerebral MRI}

In women with $\mathrm{AD}$ and a reported history of hypertensive disorders of pregnancy, we performed file searches and described their cerebral MRI scans. MRIs were acquired on a 3-tesla whole-body MR system (MR750, GE Medical Systems, Milwaukee, Wis., USA; Ingenuity TF PET/MR, Philips Medical Systems, Best, The Netherlands; Titan, Toshiba Medical Systems, Japan). The standard MRI protocol included a sagittal 3-D heavily T1-weighted gradient-echo sequence with coronal reformats, a sagittal 3-D T2-weighted fluid-attenuated inversion recovery turbo/fast spin echo with axial reformats, a transverse T2-weighted turbo/fast spin echo and a transverse T2* susceptibility sequence. All sequences were performed with wholebrain coverage.

An experienced neuroradiologist reviewed all the scans. Temporal lobe atrophy (MTA) was scored from 0 to 4 (score 0 , no atrophy; score 1, only widening of choroid fissure; score 2 , also widening of temporal horn of lateral ventricle; score 3, moderate loss of hippocampal volume (decrease in height); score 4, severe volume loss of the hippocampus). Global cortical atrophy (GCA) was scored from 0 to 3 ( 0 , no cortical atrophy; 1 , mild atrophy: opening of sulci; 2, moderate atrophy: volume loss of gyri; 3 , severe (end-stage) atrophy: 'knife blade' atrophy).

White matter hyperintensities were rated using the Fazekas score and classified as punctuate (grade 1), beginning confluent (grade 2) or confluent (grade 3) [30]. The number of microbleeds was counted on $\mathrm{T} 2 *$ sequences; they were defined as small round foci of hypointense signal, up to $10 \mathrm{~mm}$ in brain parenchyma [31]. The numbers of infarctions were also counted.

Inter- and intrarater weighted kappas of at least 0.80 for MTA, 0.60 for GCA and 0.70 for Fazekas (against internally established gold standard) were required [32]. For microbleed count, weighted Cohen's kappas are >0.90 [31, 32]. 
Abheiden et al.: Hypertensive Disorders of Pregnancy Appear Not to Be Associated with Alzheimer's Disease Later in Life

\section{Sample Size Considerations and Statistical Analysis}

In the general Dutch population, the prevalence of hypertensive disorders of pregnancy is $8.48 \%$ (Dutch Perinatal Registry). We expected to find a prevalence of hypertensive disorders of pregnancy twice as high in women with AD compared to women without AD. Since we are, to our knowledge, the first to describe a possible relation between AD and hypertensive disorders of pregnancy, we based our power calculation on a study that investigated a 30-year cardiovascular disease risk prediction by the Framingham risk score [8]. They found an almost threefold higher risk for cardiovascular disease in women after hypertensive disorders of pregnancy compared to women with a normotensive pregnancy. We made a conservative estimation by estimating the risk for AD twice as high in women with a history of hypertensive disorders. To achieve sufficient statistical power with an alpha of 0.05 and a beta of 0.84 , a required minimum of 233 participants per group was needed (doublesided test).

To analyze baseline characteristics, the parametric Student's t test, $\chi^{2}$ test, nonparametric Mann-Whitney U test or Fisher's exact tests were used. The $\chi^{2}$ test was used to compare the presence of a reported history of hypertensive disorder of pregnancy, preeclampsia, eclampsia or pregnancy-induced hypertension between women with and without AD. The $\chi^{2}$ test was also used to compare the presence of a reported history of hypertensive disorder of pregnancy, preeclampsia, eclampsia or pregnancy-induced hypertension between women with early-onset $\mathrm{AD}$ ( $<65$ years at the moment of diagnosis) or late-onset $\mathrm{AD}$ ( $>65$ years at the moment of diagnosis). When appropriate, we conducted multiple logistic regression analyses to correct for potential confounders. Statistical analyses were performed with IBM SPSS 22.0 (SPSS Inc., Chicago, Ill., USA). Results were considered significant at the $5 \%$ level.

\section{Results}

In total, 500 women were identified from the database of the Alzheimer Center of the VU University Medical Center; 251 women with AD and 249 women with a partner with AD. The overall response rate was $85.2 \%, 201$ women with $\mathrm{AD}$ and 225 women without $\mathrm{AD}$, consisting of 102 women responding to paper surveys in each group (40.6 and 40.9\%, respectively), and 99 (39.4\%) women with $\mathrm{AD}$ and 123 (49.4\%) women without AD responding to telephone survey. Of these 426 women, we excluded 169 women: 28 women due to nulliparity, 16 women due to diagnoses of dementia different from AD (e.g. vascular dementia or mild cognitive impairment), 32 women were not willing or able to participate in the study (e.g. they could not answer the questions themselves anymore, carers did not have the time for it), 9 women were deceased, 57 participants gave incomplete responses, 9 men had no (female) partner, and finally 18 women were nonresponders due to other reasons (e.g. they had a new partner who did not know anything about the pregnancies of his wife). As described in figure 1 , a total of 257 women were analyzed, 118 women with AD and 139 without. Of the women with $\mathrm{AD}, 43.2 \%$ were diagnosed with early-onset $\mathrm{AD}$. Thirty-one women with $\mathrm{AD}(26.5 \%)$ and $132(95.7 \%)$ without AD answered the survey themselves. In 2 paper surveys ( 1 woman with and 1 without $\mathrm{AD}$ ), the reporter was unclear. The mean time interval between the birth of the first child and the survey was 41.2 years for women with $A D$ and 39.2 years for women without AD ( $\mathrm{p}=0.12)$.

The baseline characteristics are depicted in table 1 . Women with AD were significantly older $(\mathrm{p}=0.035)$ and had a lower body mass index (BMI) when they completed the survey than women without $\mathrm{AD}(\mathrm{p}=0.014)$. Three women (with AD) reported both preeclampsia and pregnancy-induced hypertension in their history. In these cases, we classified the women with a history of preeclampsia and not with pregnancy-induced hypertension to prevent 


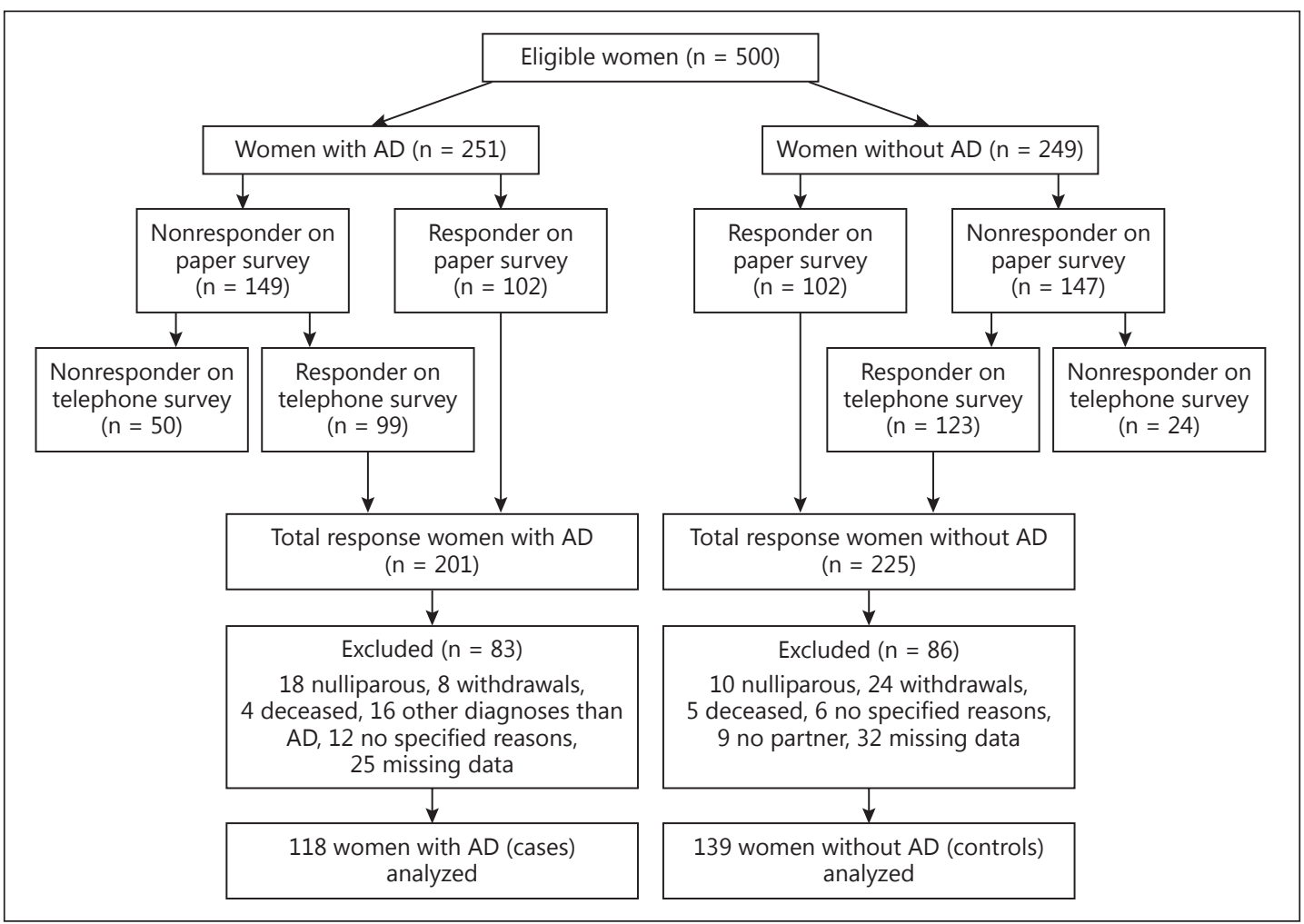

Fig. 1. Study flow diagram.

overestimation of hypertensive disorders of pregnancy. Neither mean birth weight (3,502 vs. $3,399 \mathrm{~g}$ ) nor gestational age of the firstborn differed between both groups ( $\mathrm{p}=0.30$ and $\mathrm{p}=$ 0.98 , respectively).

\section{$A D$ in Relation to Hypertensive Disorders of Pregnancy}

There was no difference between the number of women with AD reporting pregnancies complicated by hypertensive disorders and the number of women without AD (12.7 vs. $25.9 \%, \mathrm{p}=0.11$ after correction for maternal age and BMI; table 2 ). We detected no significant difference in reported histories of preeclampsia between women diagnosed with AD and those without $\mathrm{AD}$ (3.4 vs. 2.9\%, p = 1.00 after correction for age and BMI; table 2). In both groups, none of the women reported eclampsia.

Women with AD reported pregnancy-induced hypertension less often than women without $\mathrm{AD}$ ( 9.3 vs. $23.0 \%, \mathrm{p}=0.03$ after correction for age and $\mathrm{BMI}$ ). When differentiating between women with early-onset $\mathrm{AD}$ and late-onset $\mathrm{AD}, 10$ women (20.4\%) with early-onset $\mathrm{AD}$ and 3 women $(5.2 \%)$ with late-onset $\mathrm{AD}$ reported a history of hypertensive disorders of pregnancy $(p=0.02)$. Three women with AD who reported a history of preeclampsia had early-onset AD; no women with late-onset AD reported a history of preeclampsia $(p=0.03)$. Regarding the 4th woman, it is unknown if she had early-onset or late-onset AD.

We checked for report bias when comparing the rates of reported hypertensive disorders between self-reporting participants and rates reported by family members. Participants who did a self-report reported $16.1 \%$ (women with $\mathrm{AD}$ ) and $25.8 \%$ (women without $\mathrm{AD}$ ) rates of hypertensive disorders of pregnancy. Family members reported comparable rates of hypertensive disorders of pregnancy: $11.6 \%$ in women with $\mathrm{AD}$ and $33.3 \%$ in women without AD. 
Abheiden et al.: Hypertensive Disorders of Pregnancy Appear Not to Be Associated with Alzheimer's Disease Later in Life

Table 1. Baseline characteristics

\begin{tabular}{|c|c|c|c|c|c|}
\hline & \multicolumn{2}{|c|}{$\begin{array}{l}\text { Women with AD } \\
(\mathrm{n}=118)\end{array}$} & \multicolumn{2}{|c|}{$\begin{array}{l}\text { Women without AD } \\
(\mathrm{n}=139)\end{array}$} & \multirow[t]{2}{*}{$\mathrm{p}$} \\
\hline & $\mathrm{n}$ & value & $\mathrm{n}$ & value & \\
\hline Age, years & 113 & $67.1 \pm 10.6$ & 132 & $64.2 \pm 10.3$ & $0.035^{\mathrm{a}, *}$ \\
\hline BMI & 108 & $23.3(5.6)$ & 134 & $24.5(6.3)$ & $0.014^{\mathrm{b}, *}$ \\
\hline Caucasian & 117 & $108(92.3)$ & 130 & $119(91.5)$ & $0.83^{c}$ \\
\hline Smoking & 114 & $12(10.5)$ & 136 & $16(11.8)$ & $0.76^{c}$ \\
\hline Alcohol use $>1$ per day & 114 & $64(56.1)$ & 136 & $87(64.0)$ & $0.21^{\mathrm{c}}$ \\
\hline Parity & 118 & $2.5 \pm 1.0$ & 139 & $2.4 \pm 0.9$ & $0.69^{\mathrm{a}}$ \\
\hline Live births & 118 & $2.4 \pm 0.9$ & 139 & $2.4 \pm 0.9$ & $0.76^{\mathrm{a}}$ \\
\hline Self-report & 117 & $31(26.5)$ & 138 & 132 (95.7) & $<0.001^{*}$ \\
\hline Time between survey and first child, years & 110 & $41.2 \pm 9.0$ & 130 & $39.2 \pm 9.8$ & $0.12^{\mathrm{a}}$ \\
\hline Diabetes & 110 & $6(5.5)$ & 133 & $12(9.0)$ & $0.290^{\mathrm{c}}$ \\
\hline Hypercholesterolemia & 110 & $20(18.2)$ & 132 & $25(18.9)$ & $0.88^{\mathrm{c}}$ \\
\hline Hypertension & 110 & $20(18.2)$ & 134 & $38(28.4)$ & $0.06^{\mathrm{d}}$ \\
\hline Myocardial infarction & 111 & $5(2.7)$ & 134 & $1(0.7)$ & $0.09^{\mathrm{d}}$ \\
\hline Cerebrovascular accident & 112 & $3(2.7)$ & 135 & $8(5.9)$ & $0.35^{\mathrm{c}}$ \\
\hline Renal disease & 110 & $2(1.8)$ & 133 & $7(5.3)$ & $0.19^{\mathrm{d}}$ \\
\hline Thrombosis & 110 & $3(2.7)$ & 133 & $4(3.0)$ & $1.00^{\mathrm{d}}$ \\
\hline Pulmonary embolism & 109 & $1(0.9)$ & 134 & $2(1.5)$ & $1.00^{\mathrm{d}}$ \\
\hline Brain surgery & 111 & 0 & 135 & $1(0.7)$ & $1.00^{\mathrm{d}}$ \\
\hline Gestational age of firstborn, weeks & 66 & $39.3 \pm 1.5$ & 125 & $39.3 \pm 2.5$ & $0.98^{\mathrm{a}}$ \\
\hline Birth weight of firstborn, $g$ & 58 & $3,502 \pm 656$ & 127 & $3,399 \pm 524$ & $0.30^{\mathrm{a}}$ \\
\hline
\end{tabular}

All items represent the status at time of survey. Data are presented as mean \pm standard deviation, $n(\%)$ or median (interquartile range; for BMI only). ${ }^{*} \alpha=0.05$, statistically significant. ${ }^{a}$ Independent samples t test. ${ }^{\mathrm{b}}$ Mann-Whitney test. ${ }^{\mathrm{c}} \chi^{2}$. ${ }^{\mathrm{d}}$ Fisher's exact test.

Table 2. Incidence of hypertensive disorders of pregnancy

\begin{tabular}{lcll}
\hline & $\begin{array}{l}\text { Women } \\
\text { with AD } \\
\left(\mathrm{n}=104^{\mathrm{a}}\right)\end{array}$ & $\begin{array}{l}\text { Women } \\
\text { without AD } \\
\left(\mathrm{n}=129^{\mathrm{a}}\right)\end{array}$ \\
\hline $\begin{array}{llll}\text { Hypertensive disorders of pregnancy } \\
\text { Pregnancy-induced hypertension }\end{array}$ & $15(14.4)$ & $36(27.9)$ & $0.11^{\mathrm{a}, \mathrm{b}}$ \\
Preeclampsia & $4(3.8)$ & $42(24.8)$ & $0.03^{\mathrm{a}, \mathrm{b}}$ \\
Eclampsia & 0 & 0 & $1.00^{\mathrm{a}, \mathrm{b}}$ \\
\hline
\end{tabular}

Data are presented as $\mathrm{n}(\%) .{ }^{\mathrm{a}}$ After correction for age and BMI. ${ }^{\mathrm{b}} \chi^{2}$.

\section{Cerebral MRI}

We examined the cerebral MRIs of the 4 women with AD and reported histories of preeclampsia. In table 3 , the results of the MRIs are depicted. Three of the 4 women had MTA scores of 1 or 2 in either their left or their right hemisphere. The 4th woman had a score of 0 . Two women had GCAs of 1 ; the other 2 women had scores of 0 . The Fazekas score was 0 in 3 women; in the 4th woman, the Fazekas score was 1 . No microbleeds or infarctions were seen in any of the women. 
Table 3. MRI results of 4 women with $\mathrm{AD}$ and a history of preeclampsia

\begin{tabular}{lllll}
\hline & \multicolumn{2}{l}{ Patient } & & \\
\cline { 2 - 5 } & 1 & 2 & 3 & 4 \\
\hline MTA left hemisphere & 1 & 2 & 0 & 0 \\
MTA right hemisphere & 0 & 2 & 0 & 1 \\
GCA & 1 & 0 & 1 & 0 \\
Fazekas score & 0 & 0 & 0 & 1 \\
Microbleeds & no & no & no & no \\
Infarcts & no & no & no & no \\
\hline
\end{tabular}

\section{Discussion}

We found no difference in the reported history of hypertensive disorders of pregnancy between women with and without AD. This may suggest different pathophysiological pathways of cerebrovascular damage between $\mathrm{AD}$ and hypertensive disorders of pregnancy or longer-term reversibility of white matter lesions after hypertensive disorders of pregnancy.

In a sub-analysis, we found that the preeclampsia rates reported by women with AD were comparable to those of women without AD. However, women with AD reported pregnancyinduced hypertension less frequently than women without AD. Remarkably, in women without AD, we encountered an incidence of pregnancy-induced hypertension of $25.9 \%$, much higher than in the normal population since the prevalence of hypertensive disorders of pregnancy is almost $10 \%$ and pregnancy-induced hypertension is only a part of this $10 \%$ [2, $5,6]$.

In a second sub-analysis investigating if there was a difference between women with early-onset $A D$ or late-onset $A D$, significantly more women with early-onset $A D$ reported a history of hypertensive disorders of pregnancy and preeclampsia. This result is of great interest; early-onset AD has a different etiology (more genetic load, more aggressive cognitive deterioration and less mixed pathology including white matter lesions) than general AD [43]. Our population contains a very large percentage of early-onset AD cases (43.2\%), which is probably due to the fact that the Alzheimer Center of the VU University Medical Center is a referral center.

A possible explanation for the differences in percentages in both groups could be overreporting due to recall bias. A systematic review showed that the length of recall of hypertensive disorders of pregnancy did not appear to affect recall quality (up to 30 years), though sensitivity was lower and less consistent for pregnancy-induced hypertension than for preeclampsia [41]. The difference with our study is that our participants had an average recall of 40.2 years. Overreporting of pregnancy-induced hypertension is a phenomenon described in other studies as well; however, an explanation is lacking [42, 44]. Furthermore, the difference in recall between groups could also be explained by the fact that it might be possible that women with AD do not remember their obstetric history as well as women without AD. Although the survey we used was validated $[42,45]$, it is not validated for this specific population in women with AD. It is possible that women with AD underestimated their incidence of hypertensive disorders of pregnancy, and therefore the recall bias could affect both groups: overestimation in the controls and underestimation in the women with AD. Moreover, not all women answered the survey themselves, especially in the group with women with AD. We interviewed several partners or other family members, and we included only those who remembered sufficient details about the pregnancy and delivery. The difference in recall bias between women themselves, their partners or other family members is unknown. 
A further explanation for our findings suggesting overreporting could be that hypertensive disorders of pregnancy are a heterogeneous syndrome, with a wide spectrum of clinical symptoms and differences in presentation. Some women have no complaints at all, others report some pain in their upper right quadrant of their abdomen or a headache, and some women need to go to the intensive care unit because they feel very sick. Also, the definition medical staff use for pregnancy-induced hypertension (systolic blood pressure $\geq 140$ $\mathrm{mm} \mathrm{Hg}$ and/or diastolic blood pressure $\geq 90 \mathrm{~mm} \mathrm{Hg}$ measured on two occasions $6 \mathrm{~h}$ apart [46]), could be stricter than the definition patients apply.

The clinical implications of cerebral white matter lesions in young women with a history of preeclampsia and eclampsia are unknown, as are the exact causes and long-term consequences of previously found cognitive complaints in these women. To our knowledge, there are only 2 studies that report a link between preeclampsia and AD [47, 48]. The data of the first study indicate that the STOX1 gene controls a conserved pathway shared between placenta and brain with overexpression in late-onset AD. A difference with our study is that the women with AD in our study who reported preeclampsia all had early-onset AD [47].

In the second study, the authors found that women with preeclampsia exhibited urine congophilia, whereas healthy pregnant women did not [48]. This is a marker of protein instability and misfolding and has been used as a postmortem histological indicator of Alzheimer's amyloid- $\beta$ deposits in the brain of AD patients $[49,50]$.

The number of women with AD and a history of preeclampsia was low; therefore, the number of MRIs we could describe was also low. From the MRIs we could examine, 1 of the 4 women had white matter lesions. In comparison to the studies mentioned before, the time frame between a hypertensive pregnancy and cerebral imaging is longer [19-21]. In these studies, the MRI was performed much sooner after pre(eclampsia) than in our study, i.e. on average 7 years after pregnancy. To draw any conclusions about a relationship between hypertensive disorders of pregnancy and white matter lesions in $\mathrm{AD}$, a larger study needs to be performed. Since earlier studies showed an association between pre(eclampsia) and white matter lesions on average 7 years after pregnancy [19-21], we expect a relationship between hypertensive disorders of pregnancy and white matter lesions in older age.

Alternatively, the pathophysiological effects of hypertensive disorders of pregnancy on cerebrovascular function might, after all, be completely reversible over a couple of decades. To our knowledge, no studies have been performed to investigate white matter lesions after pregnancy-induced hypertension.

The strength of our study is the novelty of the subject; to our knowledge, no other studies have been performed to investigate if patients with AD had a higher prevalence of hypertensive disorders of pregnancy in their histories. Furthermore, we had a large response rate of $85.2 \%$. One of the limitations of our study is its design (a case-control study). Preferably, we would have performed a prospective study. Still, we believe that for this topic an explorative study is currently the best approach taking into account the time limitations of a prospective study. Also, the number of patients with AD and a reported history of hypertensive disorders of pregnancy was low; we need larger samples of these subjects to assess white matter lesions on the MRI level to draw conclusions. Moreover, we did not achieve our power criteria; based on the prevalence of hypertensive disorders of pregnancy of $8.48 \%$ according to the Dutch Perinatal Registry, we aimed to include 233 women per group but were able to include only 118 and 139 women in each group. In this study, we only included women with AD since the number of women with vascular dementia was low $(n=6)$, and we preferred to keep our group homogeneous. In future studies, it would be interesting to focus also on the women with vascular dementia because demented patients with a large vascular burden could be the population in which a hypertensive disorder during pregnancy has the biggest effect. 


\section{Conclusion}

No association between a reported history of hypertensive disorders of pregnancy and $\mathrm{AD}$ later in life was found in this study. In addition, we found no association between preeclampsia and $\mathrm{AD}$. Women with $\mathrm{AD}$ reported pregnancy-induced hypertension less often than women without AD, possibly due to recall bias and lack of power. Moreover, women with early-onset AD reported a history of hypertensive disorders of pregnancy and preeclampsia significantly more often than women with late-onset AD. Future research is needed to identify whether there is an association between cerebrovascular damage after hypertensive disorder of pregnancy and early-onset and/or late-onset AD.

\section{Acknowledgements}

We would like to thank all the women who participated in this study. Desiree van der Mast, Ingrid van der Zee, the nurses and midwifes of the IJsselland hospital are thanked for their help with sending the questionnaires. The database of the VU University Alzheimer Center was set up with the support of Stichting Dioraphte.

\section{Disclosure Statement}

The authors state that they have no conflicts of interest.

\section{References}

1 Elatrous S, Nouira S, Ouanes BL, Marghli S, Boussarssar M, Sakkouhi M, Abroug F: Short-term treatment of severe hypertension of pregnancy: prospective comparison of nicardipine and labetalol. Intensive Care Med 2002;28:1281-1286.

2 Sibai BM: Diagnosis and management of gestational hypertension and preeclampsia. Obstet Gynecol 2003; 102:181-192.

-3 Koopmans CM, Bijlenga D, Groen H, et al: Induction of labour versus expectant monitoring for gestational hypertension or mild pre-eclampsia after 36 weeks' gestation (HYPITAT): a multicentre, open-label randomised controlled trial. Lancet 2009;374:979-988.

-4 Schutte JM, Steegers EA, Schuitemaker NW, Santema JG, de Boer K, Pel M, Vermeulen G, Visser W, van Roosmalen J: Rise in maternal mortality in the Netherlands. BJOG 2010;117:399-406.

5 Sibai B, Dekker G, Kupferminc M: Pre-eclampsia. Lancet 2005;365:785-799.

-6 Hanff LM, Visser W, Roofthooft DW, Vermes A, Hop WC, Steegers EA, Vulto AG: Insufficient efficacy of intravenous ketanserin in severe early-onset pre-eclampsia. Eur J Obstet Gynecol Reprod Biol 2006;128:199-203.

7 Steegers EA, von Dadelszen P, Duvekot JJ, Pijnenborg R: Pre-eclampsia. Lancet 2010;376:631-644.

-8 Hermes W, Tamsma JT, Grootendorst DC, Franx A, van der Post J, van Pampus MG, Bloemenkamp KW, Porath M, Mol BW, de Groot CJ: Cardiovascular risk estimation in women with a history of hypertensive pregnancy disorders at term: a longitudinal follow-up study. BMC Pregnancy Childbirth 2010;13:126.

-9 Hermes W, Franx A, van Pampus MG, Bloemenkamp KW, Bots ML, van der Post JA, Porath M, Ponjee GA, Tamsma JT, Mol BW, de Groot CJ: Cardiovascular risk factors in women who had hypertensive disorders late in pregnancy: a cohort study. Am J Obstet Gynecol 2013;208:474-478.

$\checkmark 10$ Bellamy L, Casas JP, Hingorani AD, Williams DJ: Pre-eclampsia and risk of cardiovascular disease and cancer in later life: systematic review and meta-analysis. BMJ 2007;335:974.

11 Chesley LC: Recognition of the long-term sequelae of eclampsia. Am J Obstet Gynecol 2000;182:249-250.

12 Harskamp RE, Zeeman GG: Preeclampsia: at risk for remote cardiovascular disease. Am J Med Sci 2007;334: 291-295.

13 Giguere Y, Charland M, Theriault S, Bujold E, Laroche M, Rousseau F, Lafond J, Forest JC: Linking preeclampsia and cardiovascular disease later in life. Clin Chem Lab Med 2012;50:985-993.

14 Williams D: Long-term complications of preeclampsia. Semin Nephrol 2011;31:111-122.

15 Aukes AM, Wessel I, Dubois AM, Aarnoudse JG, Zeeman GG: Self-reported cognitive functioning in formerly eclamptic women. Am J Obstet Gynecol 2007;197:365-366. 
16 Baecke M, Spaanderman ME, van der Werf SP: Cognitive function after pre-eclampsia: an explorative study. Psychosom Obstet Gynaecol 2009;30:58-64.

17 Postma IR, Bouma A, Ankersmit IF, Zeeman GG: Neurocognitive functioning following preeclampsia and eclampsia: a long-term follow-up study. Am J Obstet Gynecol 2014;211:37-39.

18 Postma IR, Groen H, Easterling TR, Tsigas EZ, Wilson MI, Porcel J, Zeeman GG: The Brain Study: cognition, quality of life and social functioning following preeclampsia; an observational study. Pregnancy Hypertens 2013;3:227-234.

19 Aukes AM, de Groot JC, Aarnoudse JG, Zeeman GG: Brain lesions several years after eclampsia. Am J Obstet Gynecol 2009;200:504-505.

20 Aukes AM, de Groot JC, Wiegman MJ, Aarnoudse JG, Sanwikarja GS, Zeeman GG: Long-term cerebral imaging after pre-eclampsia. BJOG 2012;119:1117-1122.

21 Wiegman MJ, Zeeman GG, Aukes AM, Bolte AC, Faas MM, Aarnoudse JG, de Groot JC: Regional distribution of cerebral white matter lesions years after preeclampsia and eclampsia. Obstet Gynecol 2014;123:790-795.

-22 Postma IR, de Groot JC, Aukes AM, Aarnoudse JG, Zeeman GG: Cerebral white matter lesions and perceived cognitive dysfunction: the role of pregnancy. Am J Obstet Gynecol 2014;211:257-265.

23 Waldorff FB, Siersma V, Vogel A, Waldemar G: Subjective memory complaints in general practice predicts future dementia: a 4-year follow-up study. Int J Geriatr Psychiatry 2012;27:1180-1188.

24 Barnes LL, Schneider JA, Boyle PA, Bienias JL, Bennett DA: Memory complaints are related to Alzheimer disease pathology in older persons. Neurology 2006;67:1581-1585.

25 Minett TS, Dean JL, Firbank M, English P, O’Brien JT: Subjective memory complaints, white-matter lesions, depressive symptoms, and cognition in elderly patients. Am J Geriatr Psychiatry 2005;13:665-671.

-26 Van der Flier WM, Pijnenburg YA, Schoonenboom SN, Dik MG, Blankenstein MA, Scheltens P: Distribution of APOE genotypes in a memory clinic cohort. Dement Geriatr Cogn Disord 2008;25:433-438.

-27 Perrotin A, Mormino EC, Madison CM, Hayenga AO, Jagust WJ: Subjective cognition and amyloid deposition imaging: a Pittsburgh Compound B positron emission tomography study in normal elderly individuals. Arch Neurol 2012;69:223-229.

28 Mosconi L, Pupi A, De Leon MJ: Brain glucose hypometabolism and oxidative stress in preclinical Alzheimer's disease. Ann NY Acad Sci 2008;1147:180-195.

-29 Mark RE, Sitskoorn MM: Are subjective cognitive complaints relevant in preclinical Alzheimer's disease? A review and guidelines for healthcare professionals. Rev Clin Gerontol 2013;23:61-74.

-30 de Groot JC, de Leeuw FE, Oudkerk M, van Gijn J, Hofman A, Jolles J, Breteler MM: Cerebral white matter lesions and cognitive function: the Rotterdam Scan Study. Ann Neurol 2000;47:145-151.

-31 de GrootJC, de Leeuw FE, Oudkerk M, van Gijn J, Hofman A, Jolles J, Breteler MM: Periventricular cerebral white matter lesions predict rate of cognitive decline. Ann Neurol 2002;52:335-341.

-32 Kimura N, Nakama H, Nakamura K, Aso Y, Kumamoto T: Relationship between white matter lesions and progression of cognitive decline in Alzheimer's disease. Dement Geriatr Cogn Dis Extra 2013;3:96-101.

-33 de Leeuw FE, de Groot JC, Oudkerk M, Witteman JC, Hofman A, van Gijn J, Breteler MM: A follow-up study of blood pressure and cerebral white matter lesions. Ann Neurol 1999;46:827-833.

-34 Breteler MM, van Swieten JC, Bots ML, Grobbee DE, Claus JJ, van den Hout JH, van Harskamp F, Tanghe HL, de Jong PT, van Gijn J: Cerebral white matter lesions, vascular risk factors, and cognitive function in a populationbased study: the Rotterdam Study. Neurology 1994;44:1246-1252.

-35 Longstreth WT Jr, Manolio TA, Arnold A, Burke GL, Bryan N, Jungreis CA, Enright PL, O’Leary D, Fried L: Clinical correlates of white matter findings on cranial magnetic resonance imaging of 3,301 elderly people. The Cardiovascular Health Study. Stroke 1996;27:1274-1282.

-36 Pantoni L, Garcia JH: The significance of cerebral white matter abnormalities 100 years after Binswanger's report. A review. Stroke 1995;26:1293-1301.

37 Miyakawa T: Vascular pathology in Alzheimer's disease. Psychogeriatrics 2010;10:39-44.

-38 Miyakawa T, Kimura T, Hirata S, Fujise N, Ono T, Ishizuka K, Nakabayashi J: Role of blood vessels in producing pathological changes in the brain with Alzheimer's disease. Ann NY Acad Sci 2000;903:46-54.

-39 Stefanova E, Pavlovic A, Jovanovic Z, Veselinovic N, Despotovic I, Stojkovic T, Sternic N, Kostic V: Vascular risk factors in Alzheimer's disease - preliminary report. J Neurol Sci 2012;322:166-169.

40 Kelleher RJ, Soiza RL: Evidence of endothelial dysfunction in the development of Alzheimer's disease: is Alzheimer's a vascular disorder? Am J Cardiovasc Dis 2013;3:197-226.

-41 Stuart JJ, Bairey Merz CN, Berga SL, Miller VM, Ouyang P, Shufelt CL, Steiner M, Wenger NK, Rich-Edwards JW: Maternal recall of hypertensive disorders in pregnancy: a systematic review. J Womens Health (Larchmt) 2013;22:37-47.

42 Coolman M, de Groot CJ, Jaddoe VW, Hofman A, Raat H, Steegers EA: Medical record validation of maternally reported history of preeclampsia. J Clin Epidemiol 2010;63:932-937.

43 Panegyres PK, Chen HY: Differences between early and late onset Alzheimer's disease. Am J Neurodegener Dis 2013;2:300-306.

-44 Klemmensen AK, Olsen SF, Osterdal ML, Tabor A: Validity of preeclampsia-related diagnoses recorded in a national hospital registry and in a postpartum interview of the women. Am J Epidemiol 2007;166:117-124.

45 Diehl CL, Brost BC, Hogan MC, Elesber AA, Offord KP, Turner ST, Garovic VD: Preeclampsia as a risk factor for cardiovascular disease later in life: validation of a preeclampsia questionnaire. Am J Obstet Gynecol 2008; 198:e11-e13. 
46 Brown MA, Lindheimer MD, de Swiet M, Van Assche A, Moutquin JM: The classification and diagnosis of the hypertensive disorders of pregnancy: statement from the International Society for the Study of Hypertension in Pregnancy (ISSHP). Hypertens Pregnancy 2001;20:IX-XIV.

-47 Van Dijk M, van Bezu J, Poutsma A, Veerhuis R, Rozemuller AJ, Scheper W, Blankenstein MA, Oudejans CB: The pre-eclampsia gene STOX1 controls a conserved pathway in placenta and brain upregulated in late-onset Alzheimer's disease. J Alzheimers Dis 2010;19:673-679.

48 Buhimschi IA, Nayeri UA, Zhao G, Shook LL, Pensalfini A, Funai EF, Bernstein IM, Glabe CG, Buhimschi CS: Protein misfolding, congophilia, oligomerization, and defective amyloid processing in preeclampsia. Sci Transl Med 2014;6:245ra92.

49 Klunk WE, Jacob RF, Mason RP: Quantifying amyloid beta-peptide (Abeta) aggregation using the Congo redAbeta (CR-abeta) spectrophotometric assay. Anal Biochem 1999;266:66-76.

50 Howie AJ, Brewer DB: Optical properties of amyloid stained by Congo red: history and mechanisms. Micron 2009;40:285-301. 